\title{
Review
}

\section{Physiological roles and diseases of tmem16/ anoctamin proteins: are they all chloride channels?}

\author{
Charity DURAN, H Criss HARTZELL* \\ Emory University School of Medicine, Department of Cell Biology and Center for Neurodegenerative Disease Atlanta, GA 30322, USA
}

\begin{abstract}
The Tmem16 gene family was first identified by bioinformatic analysis in 2004 . In 2008, it was shown independently by 3 laboratories that the first two members (Tmem16A and Tmem16B) of this 10-gene family are $\mathrm{Ca}^{2+}$-activated $\mathrm{Cl}^{-}$channels. Because these proteins are thought to have 8 transmembrane domains and be anion-selective channels, the alternative name, Anoctamin (anion and octa $=8$ ), has been proposed. However, it remains unclear whether all members of this family are, in fact, anion channels or have the same 8-transmembrane domain topology. Since 2008, there have been nearly 100 papers published on this gene family. The excitement about Tmem16 proteins has been enhanced by the finding that Ano1 has been linked to cancer, mutations in Ano5 are linked to several forms of muscular dystrophy (LGMDL2 and MMD-3), mutations in Ano10 are linked to autosomal recessive spinocerebellar ataxia, and mutations in Ano6 are linked to Scott syndrome, a rare bleeding disorder. Here we review some of the recent developments in understanding the physiology and structure-function of the Tmem16 gene family.
\end{abstract}

Keywords: chloride channels; patch clamp; ion channels; channelopathies; ion transport; muscular dystrophy; ataxia; blood clotting

Acta Pharmacologica Sinica (2011) 32: 685-692; doi: 10.1038/aps.2011.48

\section{Introduction}

$\mathrm{Ca}^{2+}$-activated $\mathrm{Cl}^{-}$channels (CaCCs) play manifold roles in cell physiology ${ }^{[1,2]}$ including epithelial secretion ${ }^{[3,4]}$, sensory transduction and adaptation ${ }^{[5-8]}$, regulation of smooth muscle contraction $^{[9]}$, control of neuronal and cardiac excitability ${ }^{[10]}$, and nociception ${ }^{[11]}$. CaCCs were first described in Xenopus oocytes $^{[12,13]}$ and salamander rods ${ }^{[14]}$ in the early $1980^{\prime}$ s, but it was not until 3 years ago that the proteins responsible for these channels were identified. Prior to that, several other proteins were proposed as molecular candidates. These include ClC $-3^{[15]}, \mathrm{CLCAs}^{[16]}$, and bestrophins ${ }^{[17]}$. None of these proteins have properties that exactly fit those of classical $\mathrm{CaCCs}^{[1]}$. Although bestrophins are indeed CaCCs, their expression profile is more restricted and their biophysical properties are different from classical CaCCs ${ }^{[17]}$. So, in 2008 , the announcements that three labs had cloned genes that encoded classical CaCCs generated considerable excitement ${ }^{[18-20]}$. The two genes that have been shown definitively to encode CaCCs are called Tmem16A and Tmem16B. These are two members of a family that consists of 10 genes in mammals ${ }^{[21]}$. Yang et a ${ }^{[19]}$ proposed the new name "anoctamin" or Ano ( $\underline{\text { anion+octa }}=8$ ) and this name is now the official HUGO nomenclature and

\footnotetext{
* To whom correspondence should be addressed.

E-mail criss.hartzell@emory.edu

Received 2011-03-15 Accepted 2011-04-05
}

has replaced Tmem16 in Genbank. Tmem16A is now Ano1, Tmem16B is Ano2, and so-on except that the letter I is skipped in the Tmem16 nomenclature so that Tmem16J is Ano 9 and Tmem16K is Ano10. There is some dissatisfaction in the field with the Ano nomenclature because, as discussed below, it is not certain that all the members of this family are anion channels or have the 8-transmembrane topology. Also, the term "Ano" has a potentially objectionable meaning in the Spanish language ${ }^{[22]}$. For this reason, the Tmem16 terminology still remains in use in parallel with Ano. This review summarizes some of the recent developments in this field. The reader should consult several other outstanding reviews on Tmem16/ Ano proteins for more detail and different perspectives ${ }^{[22-29]}$.

\section{Structure-function of anoctamins}

Hydropathy analysis shows that all anoctamins have eight hydrophobic helices that are likely to be transmembrane domains with cytosolic N- and C-termini. This predicted topology has been confirmed experimentally for Ano7, whose topology has been determined using inserted HA epitope tag accessibility and endogenous N-glycosylation ${ }^{[30]}$. Although this topology is appealing, the epitope tag accessibility methodology used to identify intracellular domains of Ano7 does not clearly distinguish between intracellular domains and protein that is not efficiently trafficked to the plasma membrane. Because of this technical limitation and the fact that the topol- 
ogy of other Anos has not been experimentally determined, more investigation is required to establish the topology of these proteins.

The quaternary structure of Ano1 was recently determined to be that of a homodimer using both migration in native gels as well as Förster resonance energy transfer (FRET) ${ }^{[31,32]}$. Ano1 subunits associate before they are trafficked to the plasma membrane. The association of Ano1 subunits is likely due to noncovalent interactions, as the Ano1 assembly cannot be separated into monomers by chemical reduction with DTT. The oligomeric state is not affected by changes in intracellular $\mathrm{Ca}^{2+}$, suggesting that the homodimeric structure of Ano1 is not a determinant of channel gating. The homodimeric structure of Ano1 is reminiscent of that of CLC chloride channels, although it is not known whether the channel functions as a dimer or a higher order oligomer that is not detected quantitatively by the techniques used to date. For example, it is possible that the dimer is a biochemically stable form, but that dimerization of the dimers is required to create a functional channel. Further, it is not known whether Ano1 can form heteromers with other Anos or whether it associates with other accessory subunits. It will be interesting to see if Ano1 subunits assemble to form a single functional pore, or if each subunit contains a separate $\mathrm{Cl}^{-}$conduction pathway, similar to the double barrel structure of CLC channels.

\section{Multiple isoforms}

At least 4 splice variants have been identified for $A n o 1^{[33]}$ and two splice variants have been found for Ano7 ${ }^{[34]}$. Human Ano1 has 4 different alternatively-spliced segments, $\boldsymbol{a}, \boldsymbol{b}, \boldsymbol{c}$, and $d$ corresponding, respectively, to an alternative initiation site, exon-6b, exon-13, and exon-15 $5^{[33]}$. Segments $\boldsymbol{a}$ and $\boldsymbol{b}$ are located in the N-terminus and $c$ and $d$ are in the first intracellular loop. The variant with all 4 segments is designated as Ano1abcd; the variant lacking segments $b$ and $d$, for example, is Anolac. Analysis of ESTs in Genbank predicts that several of the other Anos also have multiple splice variants. Some of these variants may not have channel functions because they are predicted to lack some or all of the transmembrane domains. For example, the short form of Ano7, which has been shown to be translationally expressed, is a short, soluble protein $^{[34]}$. The four splice variants of Ano1 exhibit different voltage-dependent and $\mathrm{Ca}^{2+}$-dependent gating properties ${ }^{[33,35]}$. Thus, alternative splicing is likely to contribute to the heterogeneity of CaCC currents observed in native tissues.

\section{Gating mechanisms of Ano1}

Ano1 is gated by both voltage and $\mathrm{Ca}^{2+}$ but examination of the sequence of Ano1 gives few clues about the sites that sense voltage or bind to $\mathrm{Ca}^{2+}$. Unlike voltage-gated channels that have amphipathic transmembrane helices with charged amino acids that serve to sense voltage, Ano1 has no such sequences. Furthermore, there are no obvious E-F hands that might serve as $\mathrm{Ca}^{2+}$ binding sites or definitive IQ domains for CaM binding. The first intracellular loop, between TMD2 and TMD3, has a large number of acidic amino acids including a stretch of 5 consecutive glutamates $\left({ }_{444} E_{E E E E}{ }_{448}\right)$ that have attracted attention as a possible $\mathrm{Ca}^{2+}$ sensor ${ }^{[35]}$. The last glutamate in this sequence is the first residue of a 4-amino acid alternatively-spliced segment $\left({ }_{448} \mathrm{EAVK}_{451}\right)$. Neutralization of the glutamates has little effect on $\mathrm{Ca}^{2+}$ sensitivity, although deletion of the alternatively-spliced segment $(\triangle \mathrm{EAVK})$ alters both voltage-dependent gating and $\mathrm{Ca}^{2+}$ sensitivity ${ }^{[33,35]}$. Thus, although the first intracellular loop plays an important role in coupling both voltage and $\mathrm{Ca}^{2+}$ binding to channel opening, it is unlikely to be the binding site for $\mathrm{Ca}^{2+}$.

If Ano1 has no $\mathrm{Ca}^{2+}$ binding site, perhaps the $\mathrm{Ca}^{2+}$ binding site is located on an accessory subunit, such as calmodulin (CaM). A recent paper reports that CaM binds to a 22-amino acid region that overlaps with the $\boldsymbol{b}$ segment in the N-terminus called CaM-BD1 and is "essential" for gating Ano $1^{[36]}$. This putative CaM binding site is not canonical, but resembles some other CaM binding sites. However, only the Ano1 splice variants containing the $\boldsymbol{b}$ segment (eg; Ano1 $a b c$ ) seems to require CaM. Ano1ac, which lacks the CaM-BD1, does not require CaM and is activated directly by $\mathrm{Ca}^{2+}$. It is curious that deletion of the $\boldsymbol{b}$ segment reveals a $\mathrm{Ca}^{2+}$ binding site that is suppressed in the variant having the CaM binding domain. Clearly, additional work is required to clarify the role of CaM in regulation of Ano1. Some endogenous $\mathrm{CaCC}$ are regulated directly by $\mathrm{Ca}^{2+}$ and others by CaM-dependent pathways ${ }^{[2,37,38]}$ and this may be explained by expression of different splice variants or isoforms. For example, the $\mathrm{Ca}^{2+}$-sensitivity of the $\mathrm{CaCC}$ in olfactory receptor neurons, which is now thought to be Ano2, is decreased by a factor of $\sim 2$ by over-expression of dominant-negative inactive CaMs, but CaM is not essential for activation ${ }^{[38]}$.

\section{Functions of Tmem16/Ano paralogs}

Anoctamins display differential temporal and spatial expression in a variety of developing tissues, suggesting they may play an important role in development ${ }^{[39-41]}$. In murine tissues, Anos 1, 6, 7, 8, 9, and 10 are expressed in a variety of epithelia, while Anos 2, 3, 4, and 5 are more restricted to neuronal and musculoskeletal tissues ${ }^{[42]}$. Ano1 and Ano2 are the only two members of the family that have been shown conclusively to be CaCCs.

\section{Ano1 is ubiquitously expressed}

Ano1 is widely expressed in virtually every kind of secretory epithelium, for example, salivary gland, pancreas, gut, mammary gland, and airway epithelium ${ }^{[18,19,43-46]}$. Ano1 knockout mice display defective $\mathrm{Ca}^{2+}$ dependent $\mathrm{Cl}^{-}$secretion in a variety of epithelia ${ }^{[44-46]}$ and Ano1 has been implicated in rotovirus-induced diarrhea ${ }^{[47]}$. In addition, Ano1 is expressed in a variety of other cell types including certain smooth muscles and sensory neurons.

\section{Ano1 is a secondary $\mathrm{Cl}^{-}$channel in airway}

The major $\mathrm{Cl}^{-}$channel in human airway is cystic fibrosis transmembrane conductance regulator (CFTR), the protein that is defective in cystic fibrosis. CaCCs have long been considered 
as a potential target for therapy of cystic fibrosis based on the idea that upregulation or activation of CaCCs might compensate for loss of CFTR in airway fluid secretion ${ }^{[48]}$. Two drugs that activate $\mathrm{CaCC}$ by elevating intracellular $\mathrm{Ca}^{2+}$ are presently in clinical trials for treating cystic fibrosis ${ }^{[49,50]}$. Recently, however, Namkung et al ${ }^{[51]}$ showed that novel Ano1 inhibitors were rather ineffective in inhibiting CaCCs in airway epithelial cells despite their efficacy in inhibiting heterologously expressed Ano1 as well as native CaCCs in salivary gland. This result is puzzling in light of the reports by several groups that Ano1 is expressed in airway epithelium and that knockout of Ano1 decreases airway secretion ${ }^{[43,44,46]}$. One possible explanation is that that Ano1 in airway is a different splice variant or has other accessory proteins that alters its pharmacological profile. Cystic fibrosis affects other tissues in addition to airway - reproductive tract, pancreas, bile duct. Ano1 is expressed in all of these tissues and may be an alternate, non-CFTR $\mathrm{Cl}^{-}$secretory pathway ${ }^{[43,44,52]}$. Although Ano1 may represent a potential target for pharmacological treatment of cystic fibrosis, one serious concern is the fact that Ano1 is so widely expressed that systemically administered drugs are likely to have widespread side-effects. Thus, it seems that any therapy that targets Ano1 may require local delivery protocols. However, the differential sensitivity of airway and salivary gland CaCCs to novel Ano1 inhibitors raises the prospect that development of subtype-specific drugs may be feasible.

\section{Ano1 is essential for gut motility}

In addition to epithelia, Ano1 is robustly expressed in interstitial cells of Cajal which are responsible for generating pacemaker activity in smooth muscle of the gut ${ }^{[43,53,54]}$. Mice homozygous for a null allele of Ano1 fail to develop slow wave activity in gastrointestinal smooth muscles. The resulting loss of gastrointestinal motility may be an important contributor to the early death of Ano1 knockout mice ${ }^{[43]}$ and decreased expression of Ano1 in interstitial cells of Cajal may contribute to gastroparesis common in diabetic patients ${ }^{[55]}$.

\section{Ano1 is expressed in certain smooth muscle cells}

Ano1 is also expressed robustly in various kinds of smooth muscle including vascular smooth muscle cells ${ }^{[43,56,57]}$. Treatment of rat pulmonary aortic smooth muscle cells with siRNA against Ano1 results in a reduction of $\mathrm{CaCCs}^{[56]}$. Ano1 is also strongly expressed in airway smooth muscle cells, suggesting the possibility that this channel might be involved in asthma. Asthma is characterized by disorders of smooth muscle $\mathrm{Ca}^{2+}$ signaling and remodeling of the airway smooth muscle ${ }^{[58]}$. Considering that Ano1 is $\mathrm{Ca}^{2+}$-regulated and implicated in tracheal development ${ }^{[40]}$, a role for Ano1 in asthma deserves attention.

\section{Ano1 overexpression is associated with cancer}

Ano1 originally attracted the interest of cancer biologists because it is upregulated in several cancers ${ }^{[59-61]}$. Oncologists have recognized Ano1 by several other names including DOG1 (Discovered On GIST-1 tumor), ORAOV2 (Oral cancer
Overexpressed), and TAOS-2 (Tumor Amplified and Overexpressed). Ano1 may prove a useful tool for the diagnosis of certain cancers. Gene expression profiling identified Ano1 as being highly expressed in gastrointestinal stromal tumors (GISTs). KIT immunoreactivity has traditionally been used to differentiate GISTs from other tumors that are morphologically similar ${ }^{[62]}$. While KIT staining is highly specific for GISTs, not all GISTs display KIT immunoreactivity. Ano1 very specifically identifies a higher percentage of GIST tumors than does KIT, indicating that Ano1 may be a more robust and sensitive diagnostic biomarker for GISTs ${ }^{[63,64]}$.

In both oral and head and neck squamous cell carcinomas, amplification of the Ano1 locus is correlated with a poor outcome $^{[61,65]}$. Ano1 expression is significantly increased in patients with a propensity to develop metastases. Given the role that $\mathrm{Cl}^{-}$channels play in cell proliferation and migration, it is possible that Ano1 overexpression provides a growth or metastatic advantage to cancer cells ${ }^{[66]}$. Supporting the role of Ano1 in metastasis is that overexpression of Ano1 stimulates cell movement ${ }^{[67]}$. In contrast, silencing of Ano1 decreases cell migration; treatment of cells with CaCC blockers has a similar effect. Overexpression of Ano1 has no marked effect on cell proliferation. Although evidence suggests Ano1 may have a role in metastases, it is still possible that the chromosomal region containing Ano1 (11q13) contains other genes involved in cancer progression.

\section{Ano1 may be involved in nociception}

Ano1 is expressed in small dorsal root ganglion neurons and is implicated in mediating nociceptive signals triggered by bradykinin ${ }^{[11]}$. Bradykinin is a very potent inflammatory and pain-inducing substance that is released at sites of tissue damage or inflammation. Bradykinin acts on $\mathrm{G}_{\mathrm{q}}$-coupled $\mathrm{B} 2$ receptors to stimulate phospholipase- $\mathrm{C}, \mathrm{IP}_{3}$ production, and release of $\mathrm{Ca}^{2+}$ from intracellular stores. The elevation of intracellular $\mathrm{Ca}^{2+}$ opens CaCCs apparently encoded by Ano1. CaCC current, along with KCNQ channel activation, depolarizes and increases AP firing. Local injection of $\mathrm{CaCC}$ inhibitors attenuates the nociceptive effect of local injections of BK.

\section{Ano2 plays a role in sensory transduction}

In olfactory sensory neurons, odorants open cyclic nucleotide gated channels by binding to G-protein coupled olfactory receptors that elevate $\mathrm{cAMP}^{[6]}$. $\mathrm{Ca}^{2+}$ influx through the cyclic nucleotide gated channels then activates CaCCs that amplify the receptor potential. From immunostaining studies, it was first suggested that Best2 might be the olfactory $\mathrm{CaCC}^{[68]}$, but electrophysiological recordings from Best 2 knockout mice failed to confirm a role for Best 2 in mediating the olfactory receptor potential ${ }^{[69,70]}$. It seems Ano2 is now the best candidate for the pore-forming subunit of CaCCs in olfactory sensory neurons ${ }^{[5-7,71]}$. Ano2 generates $\mathrm{Ca}^{2+}$ activated chloride currents when expressed in heterologous systems ${ }^{[20,72]}$. Ano2 is localized in the cilia and dendritic knobs of olfactory sensory neurons and displays electrophysiological properties similar to native olfactory CaCCs. Ano2 displays similar halide per- 
meability, $\mathrm{Ca}^{2+}$ sensitivity, single-channel conductance, and rundown kinetics to native olfactory $\mathrm{CaCC}^{[5]}$. However, there are differences in channel inactivation kinetics, suggesting the possible presence of other regulatory subunits.

Release of the neurotransmitter glutamate at photoreceptor synapses is controlled by intracellular $\mathrm{Ca}^{2+}$. $\mathrm{Ca}^{2+}$-activated $\mathrm{Cl}^{-}$channels located in photoreceptor nerve terminals ${ }^{[14,73]}$ have been shown to provide a feedback control on transmitter release $^{[74]}$. Ano2 is highly expressed in photoreceptor synaptic terminals ${ }^{[8]}$. Ano2 is localized to presynaptic membranes in ribbon synapses, where it co-localizes with the adapter proteins PSD95, MPP4, and VELI3. Ano2 contains a consensus C-terminal PDZ class I binding motif that interacts with the PDZ domains of PSD95. Through this interaction, Ano2 is tethered to membrane domains along photoreceptor terminals, and may serve to regulate synaptic output in these cells. Ano1 has also been shown to be expressed in photoreceptor terminals, suggesting there may be a contribution by both proteins to CaCCs in photoreceptors ${ }^{[74]}$.

\section{Are Ano3-Ano10 chloride channels?}

With the exception of Ano1 and Ano2, the status of other anoctamin family members as channels is unclear. In the hands of many investigators, including ourselves, many of the heterologously-expressed Anos 3-10 do not produce robust currents because they are not readily trafficked to the plasma membrane. This could indicate that they have intracellular functions or are simply missing the necessary chaperone subunits to help them to the surface. In a study by Scheiber et $a l^{[42]}$, it was concluded that in addition to Ano1 and Ano2, Anos 6, 7, and 10 were $\mathrm{Cl}^{-}$channels. However, in iodide flux assays, the ATP- or ionomycin-stimulated flux reported for Anos 6, 7, and 10 were $<10 \%$ of those for Ano1. Furthermore, the short form of Ano7 (Ano7S), which is a 179 amino acid protein with no predicted transmembrane domains and very unlikely to be an ion channel, produced approximately the same flux as the long form of Ano7. No patch clamp data were reported for Ano7. Over-expression of Ano10 produced a $\mathrm{Cl}^{-}$current that was activated slowly over a time frame of 10 min. However, expression of Ano10 also suppressed maximal currents produced by Ano1. To date, no functional data have been published for Anos 3 and 4. Recently, Ano6 was reported by another lab to be a non-selective cation channel that is more permeable to $\mathrm{Ca}^{2+}$ than $\mathrm{Na}^{2+}{ }^{[75]}$. It will be interesting to discover the functions of these proteins.

\section{Ano5 mutations are linked to musculoskeletal disorders}

Mutations in Ano5 result in a spectrum of musculoskeletal disorders. Ano5 was originally identified as GDD1, the gene product mutated in a rare autosomal dominant skeletal syndrome called gnathodiphyseal dysplasia (GDD) ${ }^{[76]}$. Mutations in cysteine-356, a highly conserved cysteine in the first extracellular loop of Ano5, results in abnormal bone mineralization and bone fragility. Ano5 resides predominantly in intracellular membrane vesicles, but the nature of these compartments is still unknown ${ }^{[77]}$. Although the function of Ano5 remains to be determined, it clearly plays important roles in musculoskeletal development. Ano5 is expressed in growth-plate chondrocytes and osteoblasts at sites of active bone turnover, indicating an important role in bone formation. Ano5 is also expressed in somites and in developing skeletal muscle, and is upregulated during the skeletal muscle cell line $\mathrm{C} 2 \mathrm{Cl} 2$ myogenic differentiation.

The importance of Ano5 in skeletal muscle physiology is further highlighted by the recent finding that mutations in Ano5 produce several recessive muscular dystrophies ${ }^{[78-80]}$. Patients with a proximal limb-girdle muscular dystrophy (LGMD2L) and distal non-dysferlin Miyoshi myopathy (MMD3) carry mutations in Ano5. These mutations include a splice site and base pair duplication that result in premature stop codons, and two misense mutations, R758C and G231V. The phenotypes resulting from these mutations are reminiscent of dysferlinopathies, in which a deficiency in dysferlin causes defective skeletal muscle membrane repair. It has been suggested that chloride currents are important in membrane repair ${ }^{[8]]}$ and Ano5 may be one of the channels involved in this process. Additional evidence implicating Ano5 in the maintenance of skeletal muscle is that Ano5 expression is increased in dystrophin-deficient mdx mice, a mouse model of Duchenne muscular dystrophy. In contrast to the Duchenne muscular dystrophy phenotype, dystrophin-deficient $\mathrm{mdx}$ mice maintain their ability to regenerate muscle fibers and have reduced endomysial fibrosis ${ }^{[82]}$. The role of Ano5 in muscle membrane repair is still speculative, but determining if Ano5 functions as a chloride channel will be critical for elucidating its role in musculoskeletal pathologies (Figure 1).

\section{Ano6 plays a role in blood clotting}

Mutations in Ano6 have recently been implicated in Scott syndrome, a rare congenital bleeding disorder caused by a defect in blood coagulation ${ }^{[83]}$. In platelets, like other cell types, phosphatidylserine is located on the inner leaflet of the plasma membrane. When platelets are activated they expose phosphatidylserine on the outer leaflet of the plasma membrane to promote clotting. This redistribution of phosphatidylserine is mediated by phospholipid scramblases that transport phospholipids bildirectionally from one leaflet to the other. In patients with Scott syndrome this mechanism is defective, resulting in impaired blood clotting. Ano6 was found to be critical for $\mathrm{Ca}^{2+}$ dependent exposure of phosphatidylserine on the cell surface in $\mathrm{Ba} / \mathrm{F} 3$ platelet cells. Furthermore, a patient with Scott syndrome harbored a mutation at a spice-acceptor site of Ano6, resulting in premature termination of the protein. Cells derived from this patient did not expose phosphatidylserine in response to a $\mathrm{Ca}^{2+}$ ionophore, unlike cells derived from the patient's unaffected parents. These data imply that Ano6 is required for scramblase activity. However, the recent finding that Ano6 is a non-selective cation channel ${ }^{[75]}$ throws another wrinkle into the interpretation of these data.

\section{Ano7 is highly expressed in prostate}

Ano7, which is highly expressed in prostate, was discovered 


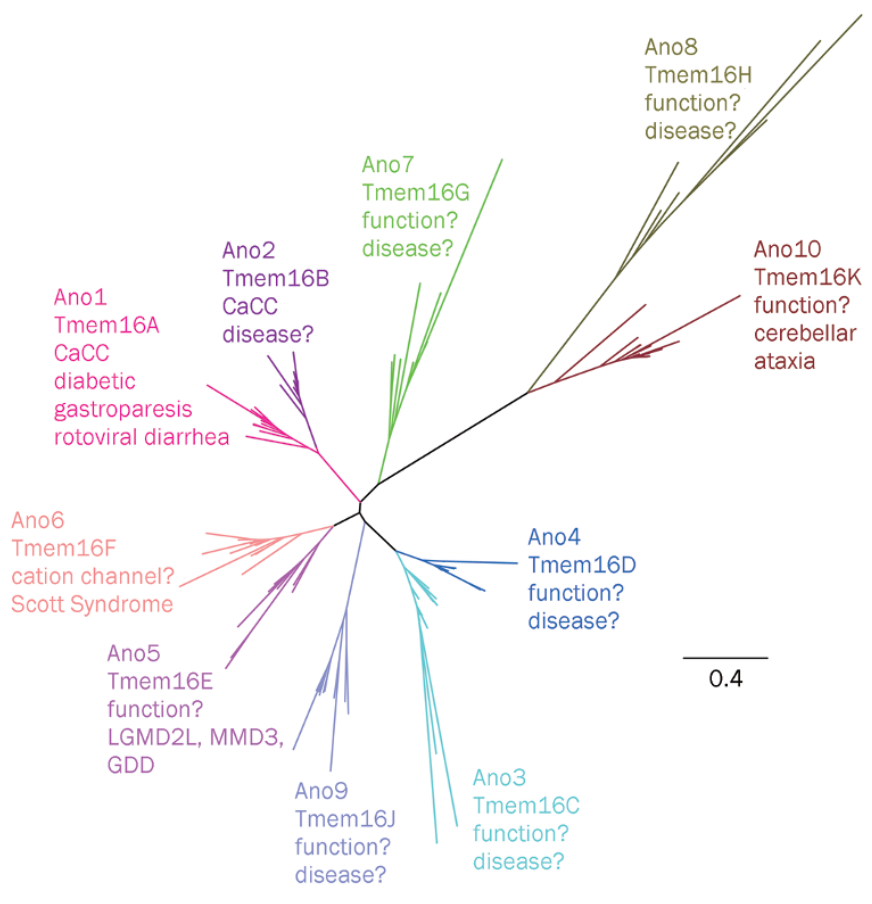

Figure 1. Phylogenetic tree of vertebrate Anoctamins. Each branch is labeled with the Ano and Tmem16 nomenclature, followed by the known or suspected physiological function, and any diseases that have been associated with this protein. GDD: gnathodiphyseal dysplasia; LGMD2L: proximal limb girdle muscular dystrophy; MMD3: distal Miyoshi muscular dystrophy. The tree was computed using 103 vertebrate Anoctamins found in Genbank and Ensembl using nearest neighbor statistics.

in a search for genes whose expression patterns mimicked those of known prostate cancer genes ${ }^{[34,84]}$. Of 40000 human genes examined, 8 novel genes, including Ano7, were identified as being the most closely linked to known prostate cancer genes. Ano7 is expressed on the apical and lateral membranes of normal prostate. In the prostate LNCaP cell line stably transfected with Ano7, the protein localizes to cell-cell contact regions. It has been suggested that Ano7 promotes cell association because cell association can be reduced with RNAi targeted to Ano $7^{[84]}$. The predominant expression in prostate and prostate cancers poise Ano7 as an attractive candidate for immunotherapy ${ }^{[85,86]}$, although the role of Ano7 in the development of prostate cancer is uncertain.

\section{Ano10 mutations are linked to ataxia}

Mutations in Ano10 have been linked to autosomal-recessive cerebellar ataxias associated with moderate gait ataxia, downbeat nystagmus, and dysarthric speech ${ }^{[87]}$. Affected individuals display severe cerebellar atrophy. Two of the mutations introduce premature stop codons, probably leading to null protein expression. The other mutation is a missense mutation, L510R, which is highly conserved among the Anos and lies in the sixth transmembrane domain within the DUF590 domain of unknown function. It remains especially uncertain whether Ano10 is an ion channel, because Ano10 and Ano8 constitute the most divergent branch of the anoctamin family. While there is little functional data for Ano10, a Drosophila ortholog of Ano8/10, called Axs, is necessary for normal spindle formation and cell cycle progression ${ }^{[88]}$. Axs co-localizes with ER components, and is recruited to microtubules of assembling spindles during mitosis and meiosis. A dominant mutation in Axs causes abnormal segregation of homologous achiasmate chromosomes due to defects in spindle formation, and disrupts cell cycle progression. It remains to be seen if Ano10 plays a similar role in mammalian systems.

\section{Summary}

The Tmem16/Anoctamin family promises to reveal many exciting secrets over the next few years. We are impatient to know whether Anos3-10 are anion channels, other types of channel, or something else, such as a phospholipid scramblase. We would also like to know whether some of these proteins have functions in intracellular organelles. It is interesting that in just $\sim 3$ years since Ano1 and Ano2 were identified as CaCCs, Anos 5, 6, and 10 have been linked to several serious human diseases, but human diseases caused by mutations in Ano1 and Ano2 have not been found. Certainly in the case of Ano1, this may be because these mutations are lethal, just as the null allele is in mice ${ }^{[40]}$. The location of the pore of the Ano1 channel still has not been clearly established. Although mutations between TMD5 and TMD6 point to the putative reentrant loop here as being part of the pore ${ }^{[18,19]}$, the remarkably high conservation in this region between Ano1, which is an anion channel, and Ano6, which is apparently a cation channel, argues against this region as a determinant of ion selectivity. Unravelling the mechanisms of Ano1 regulation by $\mathrm{Ca}^{2+}$ and voltage also remain areas that are certain to provide exciting insights.

\section{Acknowledgements}

The work in the authors' lab is supported by the National Institutes of Health grants RO1-GM60448, RO1-EY014582, and P30-EY006360. Charity DURAN is supported by an NIH Training Grant T32-EY007092.

The authors would like to thank Drs Qing-huan XIAO, Kuai YU, Patricia PEREZ-CORNEJO, and Jorge ARREOLA for helpful discussion and comments.

\section{References}

1 Duran C, Thompson CH, Xiao Q, Hartzell HC. Chloride channels: often enigmatic, rarely predictable. Annu Rev Physiol 2010; 72: 95-121.

2 Hartzell C, Putzier I, Arreola J. Calcium-activated chloride channels. Annu Rev Physiol 2005; 67: 719-58.

3 Tarran R. Regulation of airway surface liquid volume and mucus transport by active ion transport. Proc Am Thorac Soc 2004; 1: 42-6.

4 Tarran R, Loewen ME, Paradiso AM, Olsen JC, Gray MA, Argent BE, et al. Regulation of murine airway surface liquid volume by CFTR and $\mathrm{Ca}^{2+}$-activated $\mathrm{Cl}^{-}$conductances. J Gen Physiol 2002; 120: 407-18.

5 Stephan AB, Shum EY, Hirsh S, Cygnar KD, Reisert J, Zhao H. $\mathrm{ANO}_{2}$ is the cilial calcium-activated chloride channel that may mediate olfactory amplification. Proc Natl Acad Sci U S A 2009; 106: 1177681. 
6 Hengl T, Kaneko H, Dauner K, Vocke K, Frings S, Mohrlen F. Molecular components of signal amplification in olfactory sensory cilia. Proc Natl Acad Sci U S A 2010; 107: 6052-7.

7 Rasche S, Toetter B, Adler J, Tschapek A, Doerner JF, Kurtenbach S, et al. Tmem $16 \mathrm{~b}$ is specifically expressed in the cilia of olfactory sensory neurons. Chem Senses 2010; 35: 239-45.

8 Stohr H, Heisig JB, Benz PM, Schoberl S, Milenkovic VM, Strauss O, et al. TMEM16B, a novel protein with calcium-dependent chloride channel activity, associates with a presynaptic protein complex in photoreceptor terminals. J Neurosci 2009; 29: 6809-18.

9 Large WA, Wang Q. Characteristics and physiological role of the $\mathrm{Ca}^{2+}$ activated $\mathrm{Cl}^{-}$conductance in smooth muscle. Am J Physiol 1996; 271: C435-54.

10 Duan D. Phenomics of cardiac chloride channels: the systematic study of chloride channel function in the heart. J Physiol 2009; 587: 2163-77.

11 Liu B, Linley JE, Du X, Zhang X, Ooi L, Zhang H, et al. The acute nociceptive signals induced by bradykinin in rat sensory neurons are mediated by inhibition of M-type $\mathrm{K}^{+}$channels and activation of $\mathrm{Ca}^{2+}$ activated $\mathrm{Cl}^{-}$channels. J Clin Invest 2010; 120: 1240-52.

12 Barish ME. A transient calcium-dependent chloride current in the immature Xenopus oocyte. J Physiol 1983; 342: 309-25.

13 Miledi R. A calcium-dependent transient outward current in Xenopus laevis oocytes. Proc R Soc Lond B Biol Sci 1982; 215: 491-7.

14 Bader CR, Bertrand D, Schwartz EA. Voltage-activated and calciumactivated currents studied in solitary rod inner segments from the salamander retina. J Physiol 1982; 331: 253-84.

15 Huang P, Liu J, Di A, Robinson NC, Musch MW, Kaetzel MA, et al. Regulation of human CLC-3 channels by multifunctional $\mathrm{Ca}^{2+}$ / calmodulin-dependent protein kinase. J Biol Chem 2001; 276: 20093-100.

16 Loewen ME, Forsyth GW. Structure and function of CLCA proteins. Physiol Rev 2005; 85: 1061-92.

17 Hartzell HC, Qu Z, Yu K, Xiao Q, Chien LT. Molecular physiology of bestrophins: multifunctional membrane proteins linked to best disease and other retinopathies. Physiol Rev 2008; 88: 639-72.

18 Caputo A, Caci E, Ferrera L, Pedemonte N, Barsanti C, Sondo E, et al. TMEM16A, a membrane protein associated with calcium-dependent chloride channel activity. Science 2008; 322: 590-4.

19 Yang YD, Cho H, Koo JY, Tak MH, Cho Y, Shim WS, et al. TMEM16A confers receptor-activated calcium-dependent chloride conductance. Nature 2008; 455: 1210-5.

20 Schroeder BC, Cheng T, Jan YN, Jan LY. Expression cloning of TMEM16A as a calcium-activated chloride channel subunit. Cell 2008; 134: 1019-29.

21 Milenkovic VM, Brockmann M, Stohr H, Weber BH, Strauss O. Evolution and functional divergence of the anoctamin family of membrane proteins. BMC Evol Biol 2010; 10: 319.

22 Flores CA, Cid LP, Sepulveda FV, Niemeyer MI. TMEM16 proteins: the long awaited calcium-activated chloride channels? Braz J Med Biol Res 2009; 42: 993-1001.

23 Galietta LJ. The TMEM16 protein family: a new class of chloride channels? Biophys J 2009; 97: 3047-53.

24 Ferrera L, Caputo A, Galietta LJ. TMEM16A protein: a new identity for $\mathrm{Ca}^{2+}$-dependent $\mathrm{Cl}$ channels. Physiology (Bethesda) 2010; 25: 357-63.

25 Hartzell HC, Yu K, Xiao Q, Chien LT, Qu Z. Anoctamin / TMEM16 family members are $\mathrm{Ca}^{2+}$-activated $\mathrm{Cl}^{-}$channels. J Physiol Online 2009; 587: 2127-39.

26 Kunzelmann K, Kongsuphol P, Aldehni F, Tian Y, Ousingsawat J, Warth $\mathrm{R}$, et al. Bestrophin and TMEM16- $\mathrm{Ca}^{2+}$ activated $\mathrm{Cl}^{-}$channels with different functions. Cell Calcium 2009; 46: 233-41.

27 Braun AP. Cloning and expression of a calcium-activated chloride channel reveal a novel protein candidate. Channels (Austin) 2008; 2 : 393-4.

28 Galindo BE, Vacquier VD. Phylogeny of the TMEM16 protein family: some members are overexpressed in cancer. Int J Mol Med 2005; 16: 919-24.

29 Kunzelmann K, Kongsuphol P, Chootip K, Toledo C, Martins JR, Almaca J, et al. Role of the $\mathrm{Ca}^{2+}$-activated $\mathrm{Cl}^{-}$channels bestrophin and anoctamin in epithelial cells. Biol Chem 2011; 392: 125-34.

30 Das S, Hahn Y, Walker DA, Nagata S, Willingham MC, Peehl DM, et al. Topology of NGEP, a prostate-specific cell:cell junction protein widely expressed in many cancers of different grade level. Cancer Res 2008; 68: 6306-12.

31 Sheridan JT, Worthington EN, Yu K, Gabriel SE, Hartzell HC, Tarran R. Characterization of the oligomeric structure of the $\mathrm{Ca}^{2+}$-activated $\mathrm{Cl}^{-}$ channel Ano1/TMEM16A. J Biol Chem 2011; 286: 1381-8.

32 Fallah G, Romer T, Detro-Dassen S, Braam U, Markwardt F, Schmalzing G. TMEM16A(a)/anoctamin-1 shares a homodimeric architecture with CLC chloride channels. Mol Cell Proteomics 2011; 10: M110.004697.

33 Ferrera L, Caputo A, Ubby I, Bussani E, Zegarra-Moran O, Ravazzolo $\mathrm{R}$, et al. Regulation of TMEM16A chloride channel properties by alternative splicing. J Biol Chem 2009; 284: 33360-8.

34 Bera TK, Das S, Maeda H, Beers R, Wolfgang CD, Kumar V, et al. NGEP, a gene encoding a membrane protein detected only in prostate cancer and normal prostate. Proc Natl Acad Sci U S A 2004; 101: 3059-64.

35 Xiao Q, Yu K, Perez-Cornejo P, Cui Y, Arreola J, Hartzell HC. Voltageand calcium-dependent gating of tmem $16 \mathrm{a} / \mathrm{ano} 1$ chloride channels are physically coupled by the first intracellular loop. Proc Natl Acad Sci U S A 2011. doi: 10.1073/pnas.1102147108.

36 Tian Y, Kongsuphol P, Hug M, Ousingsawat J, Witzgall R, Schreiber $\mathrm{R}$, et al. Calmodulin-dependent activation of the epithelial calciumdependent chloride channel TMEM16A. FASEB J 2011; 25: 1058-68.

37 Arreola J, Melvin JE, Begenisich T. Differences in regulation of $\mathrm{Ca}^{2+}$ activated $\mathrm{Cl}^{-}$channels in colonic and parotid secretory cells. Am J Physiol 1998; 274: C161-C166.

38 Kaneko H, Mohrlen F, Frings S. Calmodulin contributes to gating control in olfactory calcium-activated chloride channels. J Gen Physiol 2006; 127: 737-48.

39 Gritli-Linde A, Vaziri Sani F, Rock JR, Hallberg K, Iribarne D, Harfe BD, et al. Expression patterns of the Tmem16 gene family during cephalic development in the mouse. Gene Expr Patterns 2009; 9: 178-91.

40 Rock JR, Futtner CR, Harfe BD. The transmembrane protein TMEM16A is required for normal development of the murine trachea. Develop Biol 2008; 321: 141-9.

41 Rock JR, Harfe BD. Expression of TMEM16 paralogs during murine embryogenesis. Develop Dynamics 2008; 237: 2566-74.

42 Schreiber R, Uliyakina I, Kongsuphol P, Warth R, Mirza M, Martins JR, et al. Expression and function of epithelial anoctamins. J Biol Chem 2010; 285: 7838-45.

43 Huang F, Rock JR, Harfe BD, Cheng T, Huang X, Jan YN, et al. Studies on expression and function of the TMEM16A calcium-activated chloride channel. Proc Natl Acad Sci U S A 2009; 106: 21413-8.

44 Ousingsawat J, Martins JR, Schreiber R, Rock JR, Harfe BD, Kunzelmann K. Loss of TMEM16A causes a defect in epithelial $\mathrm{Ca}^{2+}$ dependent chloride transport. J Biol Chem 2009; 284: 28698-703.

45 Romanenko VG, Catalan MA, Brown DA, Putzier I, Hartzell HC, Marmorstein AD, et al. Tmem16A encodes the $\mathrm{Ca}^{2+}$-activated $\mathrm{Cl}^{-}$ channel in mouse submandibular salivary gland acinar cells. J Biol Chem 2010; 285: 12990-3001. 
46 Rock JR, O'Neal WK, Gabriel SE, Randell SH, Harfe BD, Boucher RC, et al. Transmembrane protein 16A (TMEM16A) is a $\mathrm{Ca}^{2+}$-regulated $\mathrm{Cl}^{-}$secretory channel in mouse airways. J Biol Chem 2009; 284: 14875-80.

47 Ousingsawat J, Mirza M, Tian Y, Roussa E, Schreiber R, Cook DI, et al. Rotavirus toxin NSP4 induces diarrhea by activation of TMEM16A and inhibition of $\mathrm{Na}^{+}$absorption. Pflugers Arch 2011; 461: 579-89.

48 Knowles MR, Clarke LL, Boucher RC. Extracellular ATP and UTP induce chloride secretion in nasal epithelia of cystic fibrosis patients and normal subjects in vivo. Chest 1992; 101: 60S-63S.

49 Zeitlin PL, Boyle MP, Guggino WB, Molina L. A phase I trial of intranasal Moli1901 for cystic fibrosis. Chest 2004; 125: 143-9.

50 Storey S, Wald G. Novel agents in cystic fibrosis. Nat Rev Drug Discov 2008; 7: 555-6.

51 Namkung W, Phuan PW, Verkman AS. TMEM16A inhibitors reveal TMEM16A as a minor component of calcium-activated chloride channel conductance in airway and intestinal epithelial cells. J Biol Chem 2011; 286: 2365-74.

52 Dutta AK, Khimji AK, Kresge C, Bugde A, Dougherty M, Esser V, et al. Identification and functional characterization of TMEM16A, a $\mathrm{Ca}^{2+}$ activated $\mathrm{Cl}^{-}$channel activated by extracellular nucleotides, in biliary epithelium. J Biol Chem 2011; 286: 766-76.

53 Hwang SJ, Blair PJ, Britton FC, O'Driscoll KE, Hennig G, Bayguinov YR, et al. Expression of anoctamin 1/TMEM16A by interstitial cells of Cajal is fundamental for slow wave activity in gastrointestinal muscles. J Physiol 2009; 587: 4887-904.

54 Zhu MH, Kim TW, Ro S, Yan W, Ward SM, Koh SD, et al. A Ca ${ }^{2+}$ activated $\mathrm{Cl}^{-}$conductance in interstitial cells of Cajal linked to slow wave currents and pacemaker activity. J Physiol 2009; 587: 490518.

55 Mazzone A, Bernard CE, Strege PR, Beyder A, Galietta LJ, Pasricha $\mathrm{PJ}$, et al. Altered expression of ANO1 variants in human diabetic gastroparesis. J Biol Chem 2011; 286: 13393-403.

56 Manoury B, Tamuleviciute A, Tammaro P. TMEM16A/anoctamin 1 protein mediates calcium-activated chloride currents in pulmonary arterial smooth muscle cells. J Physiol 2010; 588: 2305-14.

57 Davis AJ, Forrest AS, Jepps TA, Valencik ML, Wiwchar M, Singer CA, et al. Expression profile and protein translation of TMEM16A in murine smooth muscle. Am J Physiol Cell Physiol 2010; 299: C948-59.

58 Mahn K, Ojo OO, Chadwick G, Aaronson PI, Ward JP, Lee TH. $\mathrm{Ca}^{2+}$ homeostasis and structural and functional remodelling of airway smooth muscle in asthma. Thorax 2010; 65: 547-52.

59 West RB, Corless CL, Chen X, Rubin BP, Subramanian S, Montgomery $\mathrm{K}$, et al. The novel marker, DOG1, is expressed ubiquitously in gastrointestinal stromal tumors irrespective of KIT or PDGFRA mutation status. Am J Pathol 2004; 165: 107-13.

60 Huang X, Gollin SM, Raja S, Godfrey TE. High-resolution mapping of the 11q13 amplicon and identification of a gene, TAOS1, that is amplified and overexpressed in oral cancer cells. Proc Natl Acad Sci U S A 2002; 99: 11369-74.

61 Carles A, Millon R, Cromer A, Ganguli G, Lemaire F, Young J, et al. Head and neck squamous cell carcinoma transcriptome analysis by comprehensive validated differential display. Oncogene 2006; 25 : 1821-31.

62 Espinosa I, Lee CH, Kim MK, Rouse BT, Subramanian S, Montgomery $\mathrm{K}$, et al. A novel monoclonal antibody against DOG1 is a sensitive and specific marker for gastrointestinal stromal tumors. Am J Surg Pathol 2008; 32: 210-8.

63 Hwang DG, Qian X, Hornick JL. DOG1 antibody is a highly sensitive and specific marker for gastrointestinal stromal tumors in cytology cell blocks. Am J Clin Pathol 2011; 135: 448-53.
64 Lee $\mathrm{CH}$, Liang CW, Espinosa I. The utility of discovered on gastrointestinal stromal tumor 1 (DOG1) antibody in surgical pathology-the GIST of it. Adv Anat Pathol 2010; 17: 222-32.

65 Huang X, Godfrey TE, Gooding WE, McCarty KS Jr, Gollin SM. Comprehensive genome and transcriptome analysis of the $11 q 13$ amplicon in human oral cancer and synteny to the 7F5 amplicon in murine oral carcinoma. Genes Chromosomes Cancer 2006; 45: 1058-69.

66 Kunzelmann K. Ion channels and cancer. J Membr Biol 2005; 205 : 159-73.

67 Ayoub C, Wasylyk C, Li Y, Thomas E, Marisa L, Robe A, et al. ANO1 amplification and expression in HNSCC with a high propensity for future distant metastasis and its functions in HNSCC cell lines. $\mathrm{Br} J$ Cancer 2010; 103: 715-26.

68 Pifferi S, Pascarella G, Boccaccio A, Mazzatenta A, Gustincich S, Menini A, et al. Bestrophin-2 is a candidate calcium-activated chloride channel involved in olfactory transduction. Proc Natl Acad Sci U S A 2006; 103: 12929-34.

69 Pifferi S, Dibattista M, Sagheddu C, Boccaccio A, Al Qteishat A, Ghirardi $F$, et al. Calcium-activated chloride currents in olfactory sensory neurons from mice lacking bestrophin-2. J Physiol 2009; 587: 4265-79.

70 Bakall B, McLaughlin PJ, Stanton JB, Hartzell HC, Marmorstein LY, Marmorstein AD. The bestrophin-2 knock-out mouse: histological and functional analysis. ARVO Meeting Abstracts 2007; 48: 2983.

71 Sagheddu C, Boccaccio A, Dibattista M, Montani G, Tirindelli R, Menini A. Calcium concentration jumps reveal dynamic ion selectivity of calcium-activated chloride currents in mouse olfactory sensory neurons and TMEM16b-transfected HEK 293T cells. J Physiol 2010; 588: 4189-204.

72 Pifferi S, Dibattista M, Menini A. TMEM16B induces chloride currents activated by calcium in mammalian cells. Pflugers Arch 2009; 458: 1023-38.

73 MacLeish PR, Nurse CA. Ion channel compartments in photoreceptors: evidence from salamander rods with intact and ablated terminals. J Neurophysiol 2007; 98: 86-95.

74 Mercer AJ, Rabl K, Riccardi GE, Brecha NC, Stella SL Jr, Thoreson WB. Location of release sites and calcium-activated chloride channels relative to calcium channels at the photoreceptor ribbon synapse. J Neurophysiol 2011; 105: 321-35.

75 Yang H, Jin T, Cheng T, Jan YN, Jan LY. Scan: a novel smallconductance $\mathrm{Ca}^{2+}$-activated non-selective cation channel encoded by TMEM16F. Biophys J 2011; 100: 259a.

76 Tsutsumi S, Kamata N, Vokes TJ, Maruoka Y, Nakakuki K, Enomoto $\mathrm{S}$, et al. The novel gene encoding a putative transmembrane protein is mutated in gnathodiaphyseal dysplasia (GDD). Am J Hum Genet 2004; 74: 1255-61.

77 Mizuta K, Tsutsumi S, Inoue H, Sakamoto Y, Miyatake K, Miyawaki $\mathrm{K}$, et al. Molecular characterization of GDD1/TMEM16E, the gene product responsible for autosomal dominant gnathodiaphyseal dysplasia. Biochem Biophys Res Commun 2007; 357: 126-32.

78 Hicks D, Sarkozy A, Muelas N, Koehler K, Huebner A, Hudson G, et al. A founder mutation in Anoctamin 5 is a major cause of limb-girdle muscular dystrophy. Brain 2011; 134: 171-82.

79 Bolduc V, Marlow G, Boycott KM, Saleki K, Inoue H, Kroon J, et al. Recessive mutations in the putative calcium-activated chloride channel Anoctamin 5 cause proximal LGMD2L and distal MMD3 muscular dystrophies. Am J Hum Genet 2010; 86: 213-21.

80 Mahjneh I, Jaiswal J, Lamminen A, Somer M, Marlow G, Kiuru-Enari $\mathrm{S}$, et al. A new distal myopathy with mutation in anoctamin 5. Neuromuscul Disord 2010; 20: 791-5. 
81 Fein A, Terasaki M. Rapid increase in plasma membrane chloride permeability during wound resealing in starfish oocytes. J Gen Physiol 2005; 126: 151-9.

82 Sicinski P, Geng Y, Ryder-Cook AS, Barnard EA, Darlison MG, Barnard PJ. The molecular basis of muscular dystrophy in the $\mathrm{mdx}$ mouse: a point mutation. Science 1989; 244: 1578-80.

83 Suzuki J, Umeda M, Sims PJ, Nagata S. Calcium-dependent phospholipid scrambling by TMEM16F. Nature 2010; 468: 834-8.

84 Das S, Hahn Y, Nagata S, Willingham MC, Bera TK, Lee B, et al. NGEP, a prostate-specific plasma membrane protein that promotes the association of LNCaP cells. Cancer Res 2007; 67: 1594-601.

85 Cereda V, Poole DJ, Palena C, Das S, Bera TK, Remondo C, et al. New gene expressed in prostate: a potential target for T cell-mediated prostate cancer immunotherapy. Cancer Immunol Immunother 2010; 59: 63-71.

86 Williams RM, Naz RK. Novel biomarkers and therapeutic targets for prostate cancer. Front Biosci (Schol Ed) 2010; 2: 677-84.

87 Vermeer S, Hoischen A, Meijer RP, Gilissen C, Neveling K, Wieskamp N, et al. Targeted next-generation sequencing of a $12.5 \mathrm{Mb}$ homozygous region reveals ANO10 mutations in patients with autosomal-recessive cerebellar ataxia. Am J Hum Genet 2010; 87: 813-9.

88 Kramer J, Hawley RS. The spindle-associated transmembrane protein Axs identifies a membranous structure ensheathing the meiotic spindle. Nat Cell Biol 2003; 5: 261-3. 